\title{
Systemic Treatments in Pediatric Psoriasis: A Retrospective Single-Center Study
}

\author{
Gokhan Sahin, MD ${ }^{1 *}$; Fatma Aydin, MD ${ }^{1}$; Esra Pancar Yuksel, MD \\ ${ }^{1}$ Department of Dermatology, Medical Faculty, Ondokuz Mayıs University, Samsun, Turkey
}

\begin{abstract}
Background: Systemic therapies commonly used in adult psoriasis are mostly used only off-label in children and little is known about the efficacy and tolerability of these drugs in this population. In this study, we aimed to evaluate the efficacy and safety of systemic treatments in pediatric patients with psoriasis

Methods: Data were obtained retrospectively from the Department of Dermatology, Ondokuz Mayis University, School of Medicine between 2010-2019. Our study consisted of 742 pediatric patients (age $\leq 18$ years) with psoriasis. Demographic data, adverse events of systemic treatments and healing periods were considered.

Results: A total of 195 patients received systemic treatment. The mean age of onset of disease and the initiation of systemic therapy were $9.68 \pm 4.62$ and $11.33 \pm 4.38$ years, respectively. Patients received methotrexate $(n=52,26.67 \%)$, cyclosporine $(n=18$, $9.24 \%)$, acitretin $(n=106,54.35 \%)$ and others (biologics and/or one of conventional treatments) $(n=19,9.74 \%)$ as systemic therapy. Adverse events occurred in 12 patients (incidence of $6.15 \%$, and its related 95\% confidence interval of 2.75\%, 9.56\%) and nine of them had to discontinue the medication due to those adverse events. Healing periods calculated in the remaining 186 patients were $13.25 \pm 5.87,10.85 \pm 5.67,11.05 \pm 7.00$, and $9.41 \pm 4.16$ (mean \pm SD) weeks for acitretin, methotrexate, cyclosporine, and others, respectively. No statistically significant differences were noted between the treatments regarding the healing periods. Conclusion: All treatments were effective and none of them was superior in terms of the healing period. Systemic treatments used in adults can also be used in pediatric patients with psoriasis with similar efficacy and safety rates as long as routine monitoring is provided.

Keywords: Adverse events, Efficacy, Healing period, Pediatric psoriasis, Systemic treatments

Cite this article as: Sahin G, Aydin F, Yuksel EP. Systemic treatments in pediatric psoriasis: a retrospective single-center study. Arch Iran Med. 2021;24(12):903-909. doi: 10.34172/aim.2021.135
\end{abstract}

Received: September 8, 2020, Accepted: February 20, 2021, ePublished: December 1, 2021

\section{Introduction}

Psoriasis is a chronic and complex autoimmune inflammatory skin disease. ${ }^{1,2}$ It may present at any age, but less commonly in children than adults. ${ }^{3}$ Prevalence increases roughly linearly over the life course, from $0.12 \%$ at the age of 1 to $1.2 \%$ at the age of $18 .^{4}$ The clinical picture of psoriasis in childhood resembles that of adult psoriasis; however, some clinical features are distinguishing. Facial, anogenital and palmoplantar involvements are more common with often smaller psoriasis plaques and finer and softer scales than adults. ${ }^{5,6}$ The onset of psoriasis in children often occurs as guttate psoriasis, often preceded by a streptococcal infection of the upper respiratory tract. Pediatric psoriasis, similar to adult psoriasis, might be associated with comorbidities such as psoriatic arthritis, Crohn's disease, cancer, depression, non-alcoholic fatty liver disease, metabolic syndrome and cardiovascular disorders which may contribute to morbidity and mortality in patients with psoriasis. ${ }^{6,7}$

Topical therapy, phototherapy and systemic medications are used in the treatment. The first line topical therapy in pediatric psoriasis is topical corticosteroids as indicated by large clinical experiences of dermatologists. Calcineurin inhibitors are primarily used as an alternative to topical corticosteroid treatment in areas that are at great risk for corticosteroid-induced skin atrophy, such as the face and intertriginous area. Topical vitamin D analogues can also be used topically for treatment of psoriasis. ${ }^{8}$ Calcipotriol plus betamethasone ointment and tazarotene gel have been approved for use in children $\geq 12$ years with psoriasis. However, the majority of topical treatment applications have not been approved by the Food and Drug Administration (FDA) in the pediatric population. Although phototherapy is effective in pediatric psoriasis, no reports with randomized controlled trials have been published regarding the use of phototherapy in pediatric patients with psoriasis. ${ }^{9}$ While patients with mild disease are easily controlled with topical therapy and phototherapy, patients with inadequate response, comorbidities, severe diseases, and guttate, erythrodermic, or pustular psoriasis are often difficult to treat and systemic treatment is indicated. ${ }^{9}$ In recent years, the improvement in our understanding of etiopathogenesis and awareness of comorbidities has also enhanced the decision of systemic therapy. Scoring and criteria for adult patients can be used to evaluate the severity of psoriasis in pediatric patients. ${ }^{10}$ Choices of systemic treatment include methotrexate, cyclosporine, retinoids and biologics. However, there are limited data about the efficacy and safety of these agents. Dermatologists frequently hesitate to administer 
systemic therapies because some traditional systemic drugs may carry the risk of toxicity when used in children. In addition, all systemic treatments other than biologics are currently used only off-label. Therefore, we aimed to assess systemic treatments and their efficacy and safety in pediatric patients with psoriasis.

\section{Materials and Methods}

Data were obtained retrospectively from the Department of Dermatology, Ondokuz Mayis University, School of Medicine between January 2010 and March 2019. A total of 742 pediatric patients (aged $\leq 18$ years) with clinically and/or histopathologically diagnosed psoriasis were recorded. While most of patients with mild to moderate psoriasis benefited from topical therapy and phototherapy, initiating systemic therapy seemed appropriate in children with moderate to severe psoriasis who did not benefit from these treatments. The appropriate systemic treatment was selected according to the European S3 Guideline which considers the patient's age, severity, body surface area, impact of the disease on the quality of life, psychological effects of the disease, presence of comorbidities, previous treatments and the preference of the patient and the physician..$^{10} \mathrm{~A}$ total of 195 pediatric patients who received systemic treatment were included in this study. Narrowband ultraviolet B (UVB) treatment was not considered as a systemic treatment. Systemic therapies administered included acitretin, methotrexate, cyclosporine and others (etanercept, adalimumab, ustekinumab, combinations [methotrexate and infliximab treatment in one patient and acitretin and etanercept treatment in another.]) Drugs were administered at the doses of methotrexate, $0.2-0.7 \mathrm{mg} / \mathrm{kg} / \mathrm{wk}$ up to $15 \mathrm{mg}$ week, acitretin $0.3-0.5$ $\mathrm{mg} / \mathrm{kg} / \mathrm{d}$, cyclosporine 2.5 to $5.0 \mathrm{mg} / \mathrm{kg} / \mathrm{d}$ and biologics at approved doses. All patients receiving biological therapy were resistant to conventional therapies. Routine monitoring, including clinical and laboratory analyses, was done according to the European S3 guidelines for each treatment. ${ }^{10}$

The following parameters were recorded:

- Ratio of pediatric psoriasis among all psoriasis patients and pediatric patients presenting with dermatological disorders,

- Age, gender, age at first diagnosis for all pediatric patients with psoriasis,

- Comorbidities,

- Time until the initiation of systemic treatment,

- Previous treatments, reasons for discontinuation,

- Adverse events due to systemic treatments,

- Severity of the disease before and after the last treatment,

- Healing period of last systemic treatment (Treatment was continued until clinical recovery. Clinical recovery was defined as a decrease of $75-100 \%$ in Psoriasis Area and Severity Index [PASI] without any adverse events. Healing period was defined as the time without recurrence of psoriasis lesions after discontinuation of the treatment. In patients who received more than one systemic treatment, only the last systemic treatment was considered for the calculation of the healing duration).

We compared efficacy in terms of healing duration of the last systemic treatments in the remaining 186 patients because the treatment was stopped in nine patients due to adverse events.

The SPSS 22.0 program was used for statistical analysis. Frequency distributions and descriptive statistics were used to indicate the demographic information of patients. One-way ANOVA was used for analysis of variance and Tukey's test was used to determine the difference between the last systemic groups, mean age of onset of the disease, mean age of starting systemic therapy, and mean PASI of patients before last systemic treatments. A $P$ value $<0.05$ was considered statistically significant.

The major limitations of this study were its retrospective design and biological drugs that have been used in patients' resistant to conventional therapies. In addition, since a few of the patients received different biological treatments, all of them were gathered in the others group without comparing with each other. Furthermore, some of the patients who received systemic therapy had previously received another systemic treatment for various reasons, and not all patients were naive.

\section{Results}

Totally, $15.93 \%$ of all psoriasis patients $(n: 4655)$ and $15.31 \%$ of all pediatric patients (n: 4845$)$ presenting with dermatological problems were pediatric psoriasis patients ( $n: 742$ ). A total of 742 children with psoriasis aged between 0 -18 years referred to our outpatient clinic. Of these patients, 433 were female (58.4\%) and 309 were male (41.6\%).

The mean age of onset was $11.03 \pm 4.51$ years in females, $9.99 \pm 4.79$ years in males and $10.59 \pm 4.65$ years in all patients. A total of 195 patients (106 females and 89 males) received systemic treatments (acitretin in 106, methotrexate in 52, cyclosporine in 18 , etanercept in 10 , adalimumab in 5, ustekinumab in 2 and combinations in 2 [methotrexate and infliximab, acitretin and etanercept]). Sixty-four patients $(32.83 \%)$ received one or more systemic treatments prior due to recurrence in 17 patients, no benefit in 43 , and adverse events in the remaining 4 patients. Adverse events included severe nausea, vomiting, excessive fatigue and methotrexate-induced elevated liver parameters, creatinine elevation in a patient using cyclosporine, and excessive dryness in another patient receiving acitretin. Therefore, it was necessary to switch to another systemic treatment in 64 patients. Of all 195 patients, $131(67.17 \%)$ were receiving systemic treatment for the first time.

The mean age of onset of disease and the initiation of therapy in patients receiving systemic treatment were $9.68 \pm 4.62$ and $11.33 \pm 4.38$ years, respectively. The mean duration between diagnosis and the initiation of systemic treatment was $1.68 \pm 2.59$ years. No significant 
differences were noted between the mean age of the onset of psoriasis and the mean age of the initiation of systemic therapy except between patients on methotrexate and other treatments $(P=0.04)$ and between acitretin and methotrexate $(P=0.008)$.

The mean PASI scores of patients before the initiation of treatment of acitretin, methotrexate, cyclosporine and others were $18.21 \pm 6.89,16.48 \pm 5.89,17.00 \pm 5.80$, $19.21 \pm 7.22$, respectively. No significant difference was found in the mean PASI scores of the treatment groups before starting systemic therapy. Table 1 shows the demographical data, comparison of mean PASI scores of patients receiving systemic therapy according to the treatment groups before the initiation of treatment and the differences of mean PASI scores.

Comorbidities included epilepsy in seven patients, psoriatic arthritis in seven patients, depression in two patients, atrial septal defect in two patients and the following conditions each in one patient: hypertension, proteinuria, Hirschsprung's disease, hydronephrosis, attention deficit and hyperactivity, Bartter syndrome, growth retardation, hypogonadotropic hypogonadism and gastritis.

Of 195 patients, 12 had adverse events due to treatments. The incidence of adverse events in patients receiving systemic therapy was $6.15 \%$, and its related $95 \%$ confidence interval (CI) was $(2.75 \%, 9.56 \%)$. The incidence rates of adverse events for acitretin, methotrexate, cyclosporine and others were $3.7 \%, 9.6 \%, 5.5 \%$, and $10.5 \%$, respectively. Four patients receiving acitretin developed adverse events, one of whom discontinued the treatment due to elevated liver function tests. The remaining three patients had elevated triglycerides, excessive skin rash, dizziness, but continued treatment with close follow-up. Five patients undergoing methotrexate therapy developed adverse events leading to discontinuation of therapy (elevated liver function tests in three patients, varicella infection and excessive nausea in each of the remaining two). Hypertrichosis developed in one patient under cyclosporine and the treatment was discontinued. Of two patients receiving etanercept, one had pneumonia and the other had severe throat infection; therefore, their treatment was discontinued. Systemic therapies were discontinued in a total of nine patients due to adverse events (Figure 1). Therefore, the healing period was determined in 186 patients (Table 2). The healing periods for acitretin, methotrexate, cyclosporine and others (etanercept, adalimumab, ustekinumab, combinations) were $13.25 \pm 5.87,10.85 \pm 5.67,11.05 \pm 7.00$, and $9.41 \pm 4.16$ (mean $\pm \mathrm{SD}$ ) weeks, respectively. Table 2 also shows the mean differences and 95\% CIs of the treatments. All $P$ values seemed greater than 0.05 comparing the healing period of the treatment groups (Table 2). No statistically significant difference was found between the treatment groups.

\section{Discussion}

A third of adult patients with psoriasis are diagnosed during their childhood. ${ }^{8}$ Systemic treatments might be indicated due to the severity of the disease, the impact on quality of life and possible associated comorbidities. Unfortunately, except etanercept, adalimumab and ustekinumab, systemic treatments have not been approved for childhood psoriasis. Management of these patients is based on experiences with adult psoriasis, case series, expert opinions and the use of these drugs for other indications in pediatric patients. ${ }^{11}$

Epidemiological data in childhood psoriasis are scarce and differ across studies depending on region, race and age. Pediatric psoriasis represents $12.5 \%$ of all psoriasis forms and $0.3-4.1 \%$ of all dermatoses seen in children. ${ }^{12,13}$ The ratio of pediatric psoriasis to all psoriasis patients was similar in our study. However, the ratio of pediatric psoriasis to all dermatoses was found to be higher. This may be because some specific dermatoses such as psoriasis are usually referred to our clinic whereas other pediatric dermatoses are largely monitored in the Department of Pediatrics. There are mixed reports regarding gender and mean age at diagnosis which varied between $7-10.5$ years. In our study, the mean age at diagnosis was $10.59 \pm 4.65$ years. The prevalence of pediatric psoriasis is higher in girls than boys. ${ }^{14,15}$ No significant differences were noted regarding the mean age of the onset of psoriasis (except between methotrexate and other groups) and the mean age at the initiation of systemic therapy (except between acitretin and methotrexate groups). However, there are no data indicating that the treatment efficacy might vary depending on gender, age at the initiation of systemic therapy and the onset of psoriasis. It would be more appropriate to evaluate the initial disease severity while evaluating the effectiveness of drugs and there was no significant difference in initial PASI values.

In our study, a total of 27 patients of 195 (13.86\%) who received systemic treatment were found to be accompanied by additional comorbidities. Psoriatic arthritis, cardiac disorders, Crohn's disease, malignancy, multiple sclerosis and lupus are frequent comorbidities associated with psoriasis. The incidence of psoriatic arthritis in pediatric patients has been reported to range from $0.7 \%$ to $10.5 \%{ }^{6,16}$ However, the relatively low incidence in this study might be due to different properties of the study population such as race and region. Among cardiac disorders, we detected only atrial septal defect and hypertension. No other common comorbidities were encountered other than epilepsy, proteinuria, Hirschsprung's disease, hydronephrosis, attention deficit and hyperactivity, Bartter syndrome, growth retardation, hypogonadotropic hypogonadism and gastritis which could be a coincidence. It has been reported that psychiatric disorders such as anxiety and depression have an increased prevalence in pediatric patients with psoriasis. This may be due to psoriasis itself, medications or other reasons. ${ }^{17}$ There were only two patients with psychiatric disorders in our study. Associated comorbidities are important criteria for the selection of systemic treatments in psoriasis. 


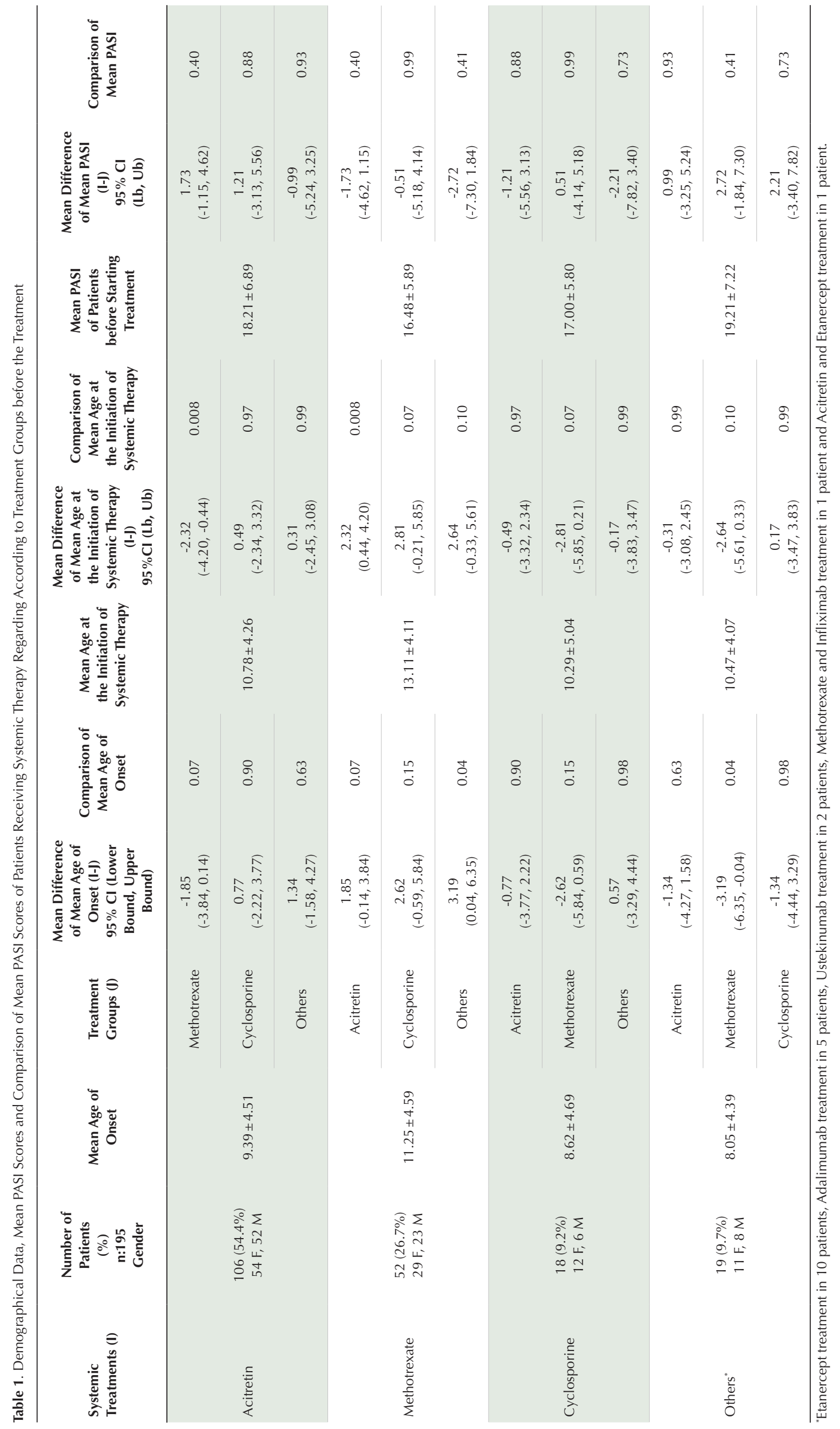


Pediatric patients with psoriasis $(n=\mathbf{7 4 2})$

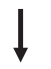

Patients who received systemic treatment $(n=195)$

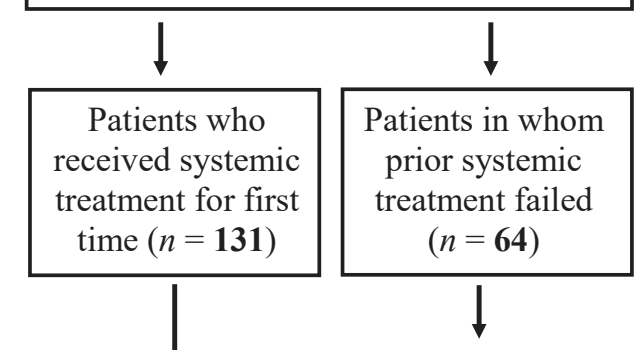

Alternative systemic treatment

- Adverse events $(n=\mathbf{1 2})$

○ Methotrexate $(n=\mathbf{5})$ : elevated liver function test, varicella, excessive nausea

- Acitretin $(n=4)$ : elevated liver function test, elevated triglycerides, excessive skin rash, dizziness

- Etanercept $(n=2)$ : pneumonia, throat infection

- Cyclosporine $(n=\mathbf{1})$ : hypertrichosis

- Discontinuation of treatment $(n=\mathbf{9})$

Figure 1. Diagram Illustrating Our Patient Population and Adverse Events Associated With Systemic Treatments.
There is vast clinical experience and expert consensus on the safe and effective use of topical therapies as first-line agents for mild to moderate psoriasis alone or in addition to systemic therapy. However, the FDA has not approved any topical medications for the treatment of psoriasis in children under 12 years. In our study, the lesions were managed to be controlled in approximately $2 / 3$ of our patients by topical treatment. However, treatment with a systemic agent needed to be initiated within a short period of time (1.68 years) after first diagnosis for the remaining $1 / 3$ of the patients. This indicates that pediatric patients may require systemic treatment earlier. In our study, $26.28 \%$ of patients received at least one systemic treatment. Studies have reported the rate of pediatric patients receiving systemic treatment at $0.35-21 \% .^{15,16}$ Phototherapy is a safe choice with relatively low systemic adverse events, but recommendation of this treatment for school-age children is limited as it requires 2-3 hospital visits per week. Seventeen patients recovered after narrowband UVB treatment whereas 13 patients displayed no benefit and switched to systemic treatments.

Conventional systemic agents such as methotrexate, cyclosporine, and acitretin for the treatment of moderate to severe psoriasis also have not been approved by FDA in children because their efficacy and safety have not been evaluated in randomized controlled trials in children. ${ }^{18}$ To date, retrospective studies have been unable to create a

Table 2. Adverse Events, Incidence of Adverse Events and their $95 \% \mathrm{Cl}$, Healing Period, and Mean Difference of Healing Period by Treatment

\begin{tabular}{|c|c|c|c|c|c|c|}
\hline $\begin{array}{l}\text { Systemic } \\
\text { Treatments (I) }\end{array}$ & Adverse Events & $\begin{array}{l}\text { Incidence of } \\
\text { Adverse Events } \\
\text { and their } 95 \% \\
\mathrm{Cl} \text { (Lower } \\
\text { Bound, Upper } \\
\text { Bound) }\end{array}$ & $\begin{array}{c}\text { Healing } \\
\text { Periods* } \\
(\text { Mean } \pm \text { SD, } \\
\text { Weeks) }\end{array}$ & $\begin{array}{c}\text { Treatment } \\
\text { Groups } \\
\text { (J) }\end{array}$ & $\begin{array}{l}\text { Mean } \\
\text { Difference } \\
\quad(I-J) \\
95 \% \text { Cl (Lower } \\
\text { Bound, Upper } \\
\text { Bound) }\end{array}$ & $\begin{array}{l}\text { Comparison of } \\
\text { Healing Periods }\end{array}$ \\
\hline \multirow{3}{*}{ Acitretin } & \multirow{3}{*}{$\begin{array}{l}\text { - One of them discontinued because of } \\
\text { elevated liver function test. } \\
\text { The other three patients had elevated } \\
\text { triglycerides, excessive skin rash, dizziness, } \\
\text { but could continue treatment with close } \\
\text { follow-up. }\end{array}$} & \multirow{3}{*}{$\begin{array}{c}3.7 \% \\
(0.09 \%, 7.46 \%)\end{array}$} & \multirow{3}{*}{$13.25 \pm 5.87$} & Methotrexate & $\begin{array}{c}2.40 \\
(-0.23,5.04)\end{array}$ & $P=0.088$ \\
\hline & & & & Cyclosporine & $\begin{array}{c}2.19 \\
(-1.73,6.13)\end{array}$ & $P=0.471$ \\
\hline & & & & Others & $\begin{array}{c}3.84 \\
(-0.08,7.77)\end{array}$ & $P=0.058$ \\
\hline \multirow{3}{*}{ Methotrexate } & \multirow{3}{*}{$\begin{array}{l}\text { - Five patients developed adverse events } \\
\text { causing discontinuation of therapy (elevated } \\
\text { liver function test in three, varicella } \\
\text { infection in one patient and excessive } \\
\text { nausea in one patient) }\end{array}$} & \multirow{3}{*}{$\begin{array}{c}9.6 \% \\
(1.3 \%, 17.9 \%)\end{array}$} & \multirow{3}{*}{$10.85 \pm 5.67$} & Acitretin & $\begin{array}{c}-2.4 \\
(-5.04,0.23)\end{array}$ & $P=0.088$ \\
\hline & & & & Cyclosporine & $\begin{array}{c}-0.20 \\
(-4.46,4.05)\end{array}$ & $P=0.999$ \\
\hline & & & & Others & $\begin{array}{c}1.43 \\
(-2.81,5.69)\end{array}$ & $P=0.817$ \\
\hline \multirow{3}{*}{ Cyclosporine } & \multirow{3}{*}{$\begin{array}{l}\text { - One patient developed hypertrichosis and } \\
\text { the treatment was discontinued. }\end{array}$} & \multirow{3}{*}{$\begin{array}{c}5.5 \% \\
(-6.1 \%, 17.2 \%)\end{array}$} & \multirow{3}{*}{$11.05 \pm 7.00$} & Acitretin & $\begin{array}{c}-2.19 \\
(-6.13,1.73)\end{array}$ & $P=0.471$ \\
\hline & & & & Methotrexate & $\begin{array}{c}0.20 \\
(-4.05,4.46)\end{array}$ & $P=0.999$ \\
\hline & & & & Others & $\begin{array}{c}1.64 \\
(-3.51,6.80)\end{array}$ & $P=0.841$ \\
\hline \multirow{3}{*}{ Others $^{* *}$} & \multirow{3}{*}{$\begin{array}{l}\text { - One of the patients receiving etanercept } \\
\text { had pneumonia and one had severe } \\
\text { throat infection; so, their treatment was } \\
\text { discontinued. }\end{array}$} & \multirow{3}{*}{$\begin{array}{c}10.5 \% \\
(-4.6 \%, 25.7 \%)\end{array}$} & \multirow{3}{*}{$9.41 \pm 4.16$} & Acitretin & $\begin{array}{l}-3.84 \\
(-7.77,0.08)\end{array}$ & $P=0.058$ \\
\hline & & & & Cyclosporine & $\begin{array}{c}-1.64 \\
(-6.80,3.51)\end{array}$ & $P=0.841$ \\
\hline & & & & Methotrexate & $\begin{array}{c}-1.43 \\
(-5.69,2.81)\end{array}$ & $P=0.817$ \\
\hline
\end{tabular}

"Nine patients discontinued treatment due to drug adverse events, calculated in 186 patients.

"Etanercept treatment in 10 patients, Adalimumab treatment in 5 patients, Ustekinumab treatment in 2 patients, Methotrexate and Infliximab treatment in 1 patient and Acitretin and Etanercept treatment in 1 patient. 
consensus or guideline on the use of traditional systemic agents. The off-label use of traditional systemic agents is based on the experience gained from the use of these medications for other pediatric indications and evidence of safety and efficacy in adult psoriasis.

There are mixed reports regarding preferred systemic agents such as acitretin or methotrexate. ${ }^{19,20}$ In one study, Bronckers et al used methotrexate in 69.2\%, biologic agents in 27.2\%, and acitretin in $14.6 \%$ of pediatric patients with psoriasis. ${ }^{3}$ Acitretin, methotrexate, cyclosporine and biologics were preferred in decreasing order of frequency in our study and acitretin was the most preferred drug as it does not have immunosuppressive properties. Some authors avoid acitretin due to possible skeletal system adverse events in long-term use. However, this is controversially debated. ${ }^{21}$ Methotrexate was used especially in patients who had psoriasis accompanied by arthritis. Cyclosporine treatment, on the other hand, was relatively less preferred as a conventional treatment due to its nephrotoxicity. The reasons for less frequent use of biological treatments may be related to the recent approval and reimbursement of drugs as well as the effective and low-cost administration of conventional treatments. There are randomized controlled trials that have found etanercept, adalimumab, and ustekinumab to be effective in pediatric psoriasis patients. ${ }^{22-24}$ Studies comparing the efficacy of biologics and conventional therapies in the treatment of pediatric psoriasis are limited. There is only one study comparing adalimumab and methotrexate in terms of efficacy in pediatric psoriasis. ${ }^{25}$ The percentage of patients in whom PASI 75 was achieved was found to be statistically significantly higher in patients treated with adalimumab. In our study, biological therapies were used in patients' resistant to conventional treatments: none of the systemic treatments were superior to each other, even biologics.

Systemic treatments can be safely administered to pediatric patients with relatively low occurrence of adverse events. Considering adverse events, discontinuation of therapy was reported mostly in cyclosporine-treated patients. ${ }^{19}$ However, the rates of drug discontinuation due to adverse events were $20 \%$ and $9.61 \%$ in patients treated with etanercept and methotrexate, respectively, in our study. We did not encounter any adverse events during switching to another systemic treatment in patients who had previously developed these adverse events. One of our patients developed varicella infection following the second dose of methotrexate injection. This undesirable situation points out the importance of vaccination in children before the initiation of immunosuppressive treatment.

In conclusion, we showed that systemic treatments commonly used in adult psoriasis could be applied in pediatric patients with psoriasis with high effectiveness and tolerability. Earlier onset of disease, length of exposure to systemic treatment, and the likelihood of comorbidities highlight the importance of choosing the appropriate systemic treatment in children. All systemic therapies included in our study were shown to be effective. No individual drug achieved superior outcomes compared to others. Patients need to be followed in terms of adverse events and the treatment can be switched off when necessary.

\section{Authors' Contribution}

FA and GS drafted the manuscript. FA and EPY performed a critical revision of the manuscript. All authors read and approved the final version of the manuscript.

\section{Conflict of Interest Disclosures}

The authors declare that they have no conflict of interest.

\section{Ethical Statement}

The study was approved by the Local Ethics Committee (2018/213).

\section{Funding}

There is no funding source.

\section{References}

1. Aydin F, Canturk T, Senturk N, Turanli AY. Methotrexate and ciclosporin combination for the treatment of severe psoriasis. Clin Exp Dermatol. 2006;31(4):520-4. doi: 10.1111/j.13652230.2006.02153.x.

2. Raychaudhuri SP, Gross J. A comparative study of pediatric onset psoriasis with adult onset psoriasis. Pediatr Dermatol. 2000;17(3):174-8. doi: 10.1046/j.1525-1470.2000.01746.x.

3. Bronckers I, Seyger MMB, West DP, Lara-Corrales I, Tollefson $M$, Tom WL, et al. Safety of systemic agents for the treatment of pediatric psoriasis. JAMA Dermatol. 2017;153(11):114757. doi: 10.1001/jamadermatol.2017.3029.

4. Augustin M, Glaeske G, Radtke MA, Christophers E, Reich K, Schäfer I. Epidemiology and comorbidity of psoriasis in children. $\mathrm{Br} J$ Dermatol. 2010;162(3):633-6. doi: 10.1111/j.1365-2133.2009.09593.x.

5. Fan X, Xiao FL, Yang S, Liu JB, Yan KL, Liang YH, et al. Childhood psoriasis: a study of 277 patients from China. J Eur Acad Dermatol Venereol. 2007;21(6):762-5. doi: 10.1111/j.14683083.2007.02014.x.

6. Mercy K, Kwasny M, Cordoro KM, Menter A, Tom WL, Korman $N$, et al. Clinical manifestations of pediatric psoriasis: results of a multicenter study in the United States. Pediatr Dermatol. 2013;30(4):424-8. doi: 10.1111/pde.12072.

7. Kimball AB, Wu EQ, Guérin A, Yu AP, Tsaneva M, Gupta SR, et al. Risks of developing psychiatric disorders in pediatric patients with psoriasis. J Am Acad Dermatol. 2012;67(4):6517.e2. doi: 10.1016/j.jaad.2011.11.948.

8. Bronckers IM, Paller AS, van Geel MJ, van de Kerkhof PC, Seyger MM. Psoriasis in children and adolescents: diagnosis, management and comorbidities. Paediatr Drugs. 2015;17(5):373-84. doi: 10.1007/s40272-015-0137-1.

9. Fortina $A B$, Bardazzi F, Berti S, Carnevale C, Di Lernia V, El Hachem $M$, et al. Treatment of severe psoriasis in children: recommendations of an Italian expert group. Eur J Pediatr. 2017;176(10):1339-54. doi: 10.1007/s00431-017-2985-x.

10. Pathirana D, Ormerod AD, Saiag P, Smith C, Spuls PI, Nast $\mathrm{A}$, et al. European S3-guidelines on the systemic treatment of psoriasis vulgaris. J Eur Acad Dermatol Venereol. 2009;23 Suppl 2:1-70. doi: 10.1111/j.1468-3083.2009.03389.x.

11. Relvas M, Torres T. Pediatric psoriasis. Am J Clin Dermatol. 2017;18(6):797-811. doi: 10.1007/s40257-017-0294-9.

12. Kumar B, Jain R, Sandhu K, Kaur I, Handa S. Epidemiology of childhood psoriasis: a study of 419 patients from northern India. Int J Dermatol. 2004;43(9):654-8. doi: 10.1111/j.13654632.2004.02182.x. 
13. Trüeb RM. Therapies for childhood psoriasis. Curr Probl Dermatol. 2009;38:137-59. doi: 10.1159/000232308.

14. Eichenfield LF, Paller AS, Tom WL, Sugarman J, Hebert AA, Friedlander SF, et al. Pediatric psoriasis: evolving perspectives. Pediatr Dermatol. 2018;35(2):170-81. doi: 10.1111/ pde.13382.

15. Kwon $\mathrm{HH}, \mathrm{Na} S$ J, Jo SJ, Youn JI. Epidemiology and clinical features of pediatric psoriasis in tertiary referral psoriasis clinic. J Dermatol. 2012;39(3):260-4. doi: 10.1111/j.13468138.2011.01452.x

16. Moustou AE, Kakourou T, Masouri S, Alexopoulos A, Sachlas A, Antoniou C. Childhood and adolescent psoriasis in Greece: a retrospective analysis of 842 patients. Int J Dermatol. 2014;53(12):1447-53. doi: 10.1111/ijd.12225.

17. Shah KN. Diagnosis and treatment of pediatric psoriasis: current and future. Am J Clin Dermatol. 2013;14(3):195-213. doi: 10.1007/s40257-013-0026-8.

18. Napolitano M, Megna M, Balato A, Ayala F, Lembo S, Villani A, et al. Systemic treatment of pediatric psoriasis: a review. Dermatol Ther (Heidelb). 2016;6(2):125-42. doi: 10.1007/ s13555-016-0117-6.

19. Charbit L, Mahé E, Phan A, Chiaverini C, Boralevi F, Bourrat $\mathrm{E}$, et al. Systemic treatments in childhood psoriasis: a French multicentre study on 154 children. Br J Dermatol. 2016;174(5):1118-21. doi: 10.1111/bjd.14326.

20. De Jager ME, Van de Kerkhof PC, De Jong EM, Seyger MM. Epidemiology and prescribed treatments in childhood psoriasis: a survey among medical professionals. J Dermatolog Treat. 2009;20(5):254-8. doi: 10.1080/09546630902911847.

21. Halverstam CP, Zeichner J, Lebwohl M. Lack of significant skeletal changes after long-term, low-dose retinoid therapy: case report and review of the literature. J Cutan Med Surg. 2006;10(6):291-9. doi: 10.2310/7750.2006.00065.

22. Paller AS, Siegfried EC, Langley RG, Gottlieb AB, Pariser D, Landells I, et al. Etanercept treatment for children and adolescents with plaque psoriasis. N Engl J Med. 2008;358(3):241-51. doi: 10.1056/NEJMoa066886.

23. Thaçi D, Papp K, Marcoux D, Weibel L, Pinter A, Ghislain PD, et al. Sustained long-term efficacy and safety of adalimumab in paediatric patients with severe chronic plaque psoriasis from a randomized, double-blind, phase III study. Br J Dermatol. 2019;181(6):1177-89. doi: 10.1111/bjd.18029.

24. Landells I, Marano C, Hsu MC, Li S, Zhu Y, Eichenfield LF, et al. Ustekinumab in adolescent patients age 12 to 17 years with moderate-to-severe plaque psoriasis: results of the randomized phase 3 CADMUS study. J Am Acad Dermatol. 2015;73(4):594-603. doi: 10.1016/j.jaad.2015.07.002.

25. Papp K, Thaçi D, Marcoux D, Weibel L, Philipp S, Ghislain PD, et al. Efficacy and safety of adalimumab every other week versus methotrexate once weekly in children and adolescents with severe chronic plaque psoriasis: a randomised, doubleblind, phase 3 trial. Lancet. 2017;390(10089):40-9. doi: 10.1016/s0140-6736(17)31189-3. 